\title{
Nitrogen-doped Graphene Electrochemical Sensor for Selenium (IV) in Water
}

\author{
Colani T Fakude ${ }^{1}$, Omotayo A Arotiba ${ }^{1,2}$, Richard Moutloali ${ }^{1,3}$, Nonhlangabezo Mabuba $^{1,2, *}$ \\ ${ }^{1}$ Department of Chemical Sciences (prior known as Department of Applied Chemistry), University of \\ Johannesburg, Doornfontein 2028, Johannesburg, South Africa, \\ ${ }^{2}$ Centre for Nanomaterials Science Research, University of Johannesburg, South Africa \\ ${ }^{3}$ Nanotechnology Innovation Centre DST/MINTEK, University of Johannesburg, South Africa \\ *E-mail: nmabuba@uj.ac.za
}

doi: $10.20964 / 2019.10 .13$

Received: 3 June 2019/ Accepted: 2 July 2019 / Published: 30 August 2019

In this study, the electrochemical detection of Se(IV) on a glassy carbon electrode (GCE) modified with nitrogen-doped graphene (NG) is reported. NG was synthesized from graphene oxide (GO) by thermal annealing of GO in ammonia. Structural and morphological studies of the synthesized NG were conducted using field emission scanning electron microscopy (FESEM), Raman spectroscopy, high resolution-transmission electron microscopy (HR-TEM), Fourier Transform -infrared spectroscopy (FTIR) and a CHNS analyzer. Electrochemical characterization of the unmodified GCE and the NG modified GCE (GCE-NG) was conducted using cyclic voltammetry (CV) and electrochemical impedance spectroscopy (EIS). The newly developed GCE-NG sensor demonstrated improved electrochemical properties when compared to the bare GCE. Square wave anodic stripping voltammetry (SWASV) was employed to optimize the proposed sensors' detection parameters: $0.1 \mathrm{M} \mathrm{HClO}_{4}$ supporting electrolyte, $-0.8 \mathrm{~V}$ deposition potential and $50 \mathrm{~s}$ deposition. The calibration graph of Se(IV) concentrations and current response demonstrated linearity during the calibration of the sensor in the concentration range $1-120 \mathrm{ppb}$, with a limit of detection (LOD) of $0.092 \mathrm{ppb}$. The proposed electrochemical sensor was applied in the analysis of real water samples and inductively coupled plasmaoptical emission spectroscopy (ICP-OES) was used to validate the results.

Keywords: Electrochemical sensor; selenium; nitrogen-doped graphene; square wave anodic stripping voltammetry

\section{$\underline{\text { FULL TEXT }}$}

(C) 2019 The Authors. Published by ESG (www.electrochemsci.org). This article is an open access article distributed under the terms and conditions of the Creative Commons Attribution license (http://creativecommons.org/licenses/by/4.0/). 